\title{
GÉNEROS POÉTICOS EN EL SIGLO DE ORO
}

\author{
But in reality genre is much \\ less of a pigeonhole than a \\ pigeon... \\ Alastair Fowler
}

Es obviamente imposible establecer un esquema estructural que distinga formal y claramente entre todos los diferentes géneros del discurso humano. Lo oral se puede oponer a lo escrito, por ejemplo, pero también se invaden mutuamente estas dos categorías de discurso; tampoco están cerradas las fronteras entre lo literario y lo no literario. Parece ser más tajante la distinción entre prosa y lenguaje versificado; la versificación, incluso la más moderna, que es a veces puramente tipográfica, impone al lector competente su propia semántica, un modo particular de entender las palabras, las cuales en prosa tendrían otro sentido'. De todas maneras, en la poesía clásica del Siglo de Oro la versificación en sí marcaba una frontera muy clara, la cual abarcaba todo un vasto terreno de discursos literarios diferentes, desde el dramático y el épico hasta el lírico, desde el obsceno hasta el amoroso y el religioso; y, además, cada tipo de versificación se asociaba con ciertos géneros poéticos, muchos de los cuales eran bastante estables. Pero, mientras el soneto se definía única y exclusivamente por su versificación, la epístola en verso, por ejemplo, se definía en primer lugar por una enunciación parecida a la de la correspondencia personal. Y la silva métrica, como Antonio Alatorre ha demostrado, no se debe confundir con el problemático género del mismo nombre, aunque sí hay relaciones entre los $\operatorname{dos}^{2}$.

${ }^{1}$ Jonathan Culler, Structuralist Poetics: Structuralism, Linguistics and the Study of Literature, Cornell University Press, Ithaca, 1975, pp. 161-164.

2 A. Alatorre, "Quevedo: de la silva al ovillejo", en HEA, pp. 19-31. 
El tomo fundacional publicado en 1543 con el título de La: obras de Boscán y algunas de Garcilasso de la Vega repartidas en quatrc libros introducía no sólo la nueva versificación italianizante sinc también todo un conjunto de nuevos géneros relacionados con ella. A esto alude Boscán ${ }^{3}$ con las palabras "materia" y "estilo" er su prólogo dirigido a la duquesa de Soma, cuando dice que la nueva versificación tiene "una disposición muy capaz para recebiı qualquier materia: o grave, o sotil, o dificultosa, o fácil, y ass: mismo para ayuntarse con qualquier estilo de los que hallamo: entre los authores antiguos aprovados". En contraste con las "co. plas castellanas"' del Cancionero general, Boscán y Garcilaso intro. ducían no sólo géneros de poesía amorosa que derivaban de la: Rime sparse de Petrarca (el soneto, la canción, el madrigal) sinc también varios géneros clásicos: la oda (en liras) y la epístola (er versos sueltos y en tercetos) de tradición horaciana, la elegíá (en tercetos), la fábula (en los versos sueltos de Boscán, má: tarde en octavas reales) y la égloga (con gran variedad métrica) ${ }^{4}$ También introducían el soneto no petrarquista que Lapesa ha lla mado soneto clásico ${ }^{5}$.

Para los poetas del Siglo de Oro no había duda de que el so neto constituía un género poético. Pero al mismo tiempo había subgéneros claramente marcados; en las palabras del teórico clá sico Francisco de Cascales ${ }^{6}$ :

... el Soneto es como el camaleón, el qual tiene las colores de st objecto: de suerte que si el objecto es verde, rojo, amarillo, o azul tal se pone el camaleón: pero con todo eso su color natural no 1 : pierde totalmente. El Soneto es tal, que si la materia, de que trata es Heroyca, será Heroyco; y por consequencia muy grave: si Có mica, será Soneto Cómico y humilde: si Trágica, será Trágico afectuoso: si la materia fuere jocosa, será Epigramático, y de nece

${ }^{3}$ Véase Obras poéticas de Juan Boscán, eds. Martín de Riquer et al., Uni versidad, Barcelona, 1957, pp. 87-91.

${ }^{4} \mathrm{Se}$ nota en todo esto la influencia de Bernardo Tasso, cuyos prólogo y géneros clásicos los tenían muy en cuenta Boscán y Garcilaso; véase mi " Not: sobre Bernardo Tasso y el manifiesto de Boscán", en Homenaje al profesor Anto nio Vilanova, eds. A. Sotelo Vázquez y M. C. Carbonell, Universidad, Barce lona, 1989, pp. 601-605.

${ }^{5}$ Véase su libro La trayectoria poética de Garcilaso, Revista de Occidente Madrid, 1968, pp. 162-166.

${ }^{6}$ Véase su Tablas poéticas (1617) en la valiosa edición comentada de AN tonio García Berrio, Introducción a la poética clasicista: Cascales, Planeta, Bar celona, 1975, p. 415. 
sidad agudo: si Satyrica, será licencioso en palabras y sentencias...

Menos teórica y más práctica sería la clasificación parecida que impuso Góngora a sus propios sonetos en el manuscrito Chacón: sacros, heroicos, morales, fúnebres, amorosos, satíricos, burlescos y varios. Estas categorías reflejaban todo el esquema jerárquico de la ideología española, tanto oficial como subversiva, o pseudosubversiva.

Ciertos sonetos de Petrarca se convertían en los modelos de otros tantos subgéneros del soneto amoroso. Su primer soneto ("Voi ch'ascoltate in rime sparse il suono"), por ejemplo, es el modelo de la palinodia o retracción que encontramos como primer soneto del cancionero petrarquista de Boscán: ' Nunca d'amor estuve tan contento"'. Algo parecido pasó con el primer soneto de Garcilaso, cuyo primer verso hermosamente retrospectivo ("Cuando me paro a contemplar mi 'stado") se repetía como primer verso de muchos otros sonetos españoles ${ }^{7}$, incluyendo la palinodia que es el primer soneto de las Rimas sacras de Lope de Vega. Más innovadores son los subgéneros del soneto clásico aislado por Lapesa en Garcilaso: el soneto 29 ("Pasando el mar Leandro el animoso"'), que desarrolla en forma de soneto el epigrama (dos dísticos) de Marcial en la muerte de Leandro; el 13 ("A Dafne ya los brazos le crecían"), que desarrolla unos versos de Ovidio; el 11 ("Hermosas ninfas que'n el río metidas"), basado en la Arcadia de Sannazaro y en las Geórgicas de Virgilio; y el 23 ("En tanto que de rosa y d'azucena"), basado en un soneto de Bernardo Tasso y en una oda de Horacio, con recuerdos del "Collige, virgo, rosas"' atribuido a Ausonio. Este último soneto de Garcilaso, sobre todo, formó escuela, es decir que constituyó un subgénero propio, al cual se ha solido ponerle la etiqueta horaciana del "carpe diem".

Inspirada por Lapesa, Blanca González de Escandón recogió en 1938 unos 50 sonetos de este subgénero; en 1979 Antonio García Berrio ha vuelto a estudiarlo con un sentido más riguroso de forma temática en su artículo titulado "Tipología textual de los sonetos clásicos españoles sobre el Carpe diem"'. En este estudio el

7 Véase el estudio de EDWARD GLASER, " "Cuando me paro a contemplar mi estado": trayectoria de un Rechenschafts-Sonett", en su libro Estudios hispanoportugueses: relaciones literarias del Siglo de Oro, Castalia, Madrid, 1957, pp. 59-95.

${ }^{8}$ Blanca GonzÁlez de Escandón, Los temas del "Carpe diem" y la brevedad de la rosa en la poesía española, Universidad, Barcelona, 1938. El artículo de GAR Cía Berrio fue publicado en Dispositio, 3 (1979), 243-293; véanse también su 
autor intenta distinguir entre dos temas relacionados: el imperativo epicúreo de disfrutar de la vida, en sonetos amorosos, y la aceptación estoica de la brevedad de la vida, en sonetos morales. Pero García Berrio reconoce que las combinaciones variadas de estos dos temas, unidos a menudo por la imagen de la rosa que representa la cara de la dama, dan origen a un número indefinido de sonetos diferentes que son a veces difíciles de clasificar con nitidez. Cualquier soneto de esta tradición, en efecto, dependiendo directa o indirectamente de los versos clásicos de Horacio y del "Collige, virgo, rosas. ..", puede representar también la transformación de un texto más reciente e inmediato.

El soneto 23 de Garcilaso, por ejemplo, parte directamente del ya mencionado soneto (1534) de Bernardo Tasso, cuyo "mentre che" inicial se repite anafóricamente en los versos 3 y 5 ; el imperativo "cogliete" del verso 6 se repite en el verso 12 , después de otra oración sintácticamente independiente que ocupa el primer terceto. Es evidente que Garcilaso quiso concentrar la sintaxis relativamente suelta de Tasso, coordinándola mejor con las divisiones principales del soneto: colocó un solo imperativo ("coged") al principio del primer terceto y eliminó una de las tres oraciones independientes de Tasso. Góngora más tarde, en su soneto que empieza "Mientras por competir con tu cabello", volvió al soneto de Tasso y continuó el proyecto sintáctico de Garcilaso, reduciendo a una sola oración compleja el soneto entero: metió el imperativo del verso 9 ("goza") entre la anáfora de "mientras" en los versos 1, 3, 5 y 7 y la cláusula temporal que empieza con "antes que" en el verso 10 , e impuso además una rigurosa correlación de cuatro facetas del cuerpo femenino con sus imágenes naturales correspondientes, convirtiéndolo todo, con el verso final, "en tierra, en humo, en polvo, en sombra, en nada". Con esto se realiza plenamente la breve trayectoria de lo que podríamos llamar el sub-subgénero tassiano del "carpe diem".

Con razón las últimas teorías feministas han señalado una importante relación entre género literario y género masculino/femenino, pues los poemas clásicos suelen ser imitaciones de actos de habla social, en los cuales influye casi siempre la condición de hombre o de mujer de los hablantes. Así es que, cuando Sor Juana Inés de la Cruz recoge la tradición del "carpe diem” en su sone-

"Macrocomponente textual y sistematismo tipológico: el soneto amoroso español en los siglos XVI y XVII y las reglas del género"', $Z R P h, 98$ (1981), 146171 y el libro que publicó con J. S. PETTÖFFI, Lingüistica del texto y crítica literaria, Comunicación, Madrid, 1979. 
to que empieza "Miró Celia una rosa que en el prado", la transforma totalmente al poner en boca de mujer el consabido imperativo: ya no es un hombre interesado que insinúa la seducción de una mujer advirtiéndole de los horrores de la vejez, ni mucho menos un hombre solitario que se resigna estoicamente a la muerte, sino una mujer que ve en la rosa a una hermana suya, o sea su propio reflejo, aconsejándole que se aproveche del tiempo (con un eco del refrán "que nos quiten lo bailado") y que se alegre de poder morir siendo todavía joven y bella. Reconocemos los viejos tópicos, pero el de Sor Juana es un soneto muy original, por su enfoque femenino, entre los muchos basados en la imagen de la rosa.

Otra imagen de los estragos del tiempo, más típicamente renacentista, es la de las ruinas de las ciudades antiguas, que traen recuerdos de la caída de los imperios y de sus culturas. Según Fucilla ${ }^{9}$, el soneto arquetípico de este subgénero es el atribuido a Castiglione que empieza con el muy imitado verso de "Superbi colli e voi, sacre ruine". En este soneto la apóstrofe de los cuartetos, dirigida a las colinas y ruinas de la ciudad de Roma, con sus tristes recuerdos de las grandes almas ya muertas y de los desaparecidos espectáculos públicos, se combina arbitrariamente en los tercetos con esta especulación: si los grandes edificios resisten por un rato los estragos del tiempo pero luego se reducen al olvido, el poeta podrá soportar los sufrimientos amorosos ya que ellos también pasarán. El intrusivo tema amoroso parece trivializar el tema más filosófico de la caída imperial; siguiendo esta convención en sus sonetos sobre las ruinas de Cartago, tanto Garcilaso ("Boscán las armas y el furor de Marte") como Cetina ("Excelso monte do el romano estrago") introducen en la poesía española la misma combinación arbitraria. Años más tarde Lope de Vega, anciano sacerdote ya disfrazado de Tomé de Burguillos, se burla de tal trivialización en su parodia que empieza con la rimbombante imitación de Castiglione: "Soberbias torre, altos edificios", y termina con este terceto y su chocante palabra final:

9 Véase JosePh G. Fucilla, "Superbi colli: notas sobre la boga del tema en España", estudio incluido en su colección de ensayos titulada Superbi Colli e altri saggi, Carucci, Roma, 1963, pp. 7-43. Véase también el trabajo más reciente de BEGOÑa López BuEno, "Tópica literaria y realización textual: unas notas sobre la poesía española de las ruinas en el Siglo de Oro", $R F E, 66$ (1986), 59-74, artículo ahora incluido en su Templada lira: cinco estudios sobre poesía del Siglo de Oro, Don Quijote, Granada, 1990, pp. 75-97; su nota 4 cita una amplia bibliografía. 
¡Oh gran consuelo a mi esperanza vana, que el tiempo que os volvió breves rüinas no es mucho que acabase mi sotana!

Pero otros poetas españoles eliminaron la introducción del tema personal, consiguiendo así una unidad más clásica. Véase, por ejemplo, el soneto de Juan de Arguijo que empieza "Este soberbio monte y levantada", el cual introduce en los tercetos la paradoja de que Cartago tiene más fama por sus ruinas, es decir, por su destrucción militar, de la que tendría si siguiera en pie. Otras paradojas más enfáticas dan unidad compacta al soneto de Quevedo escrito en imitación del de Du Bellay sobre las antigüedades de Roma ("Buscas en Roma a Roma, ¡oh peregrino!"): en los tercetos se introduce el río Tíber como más permanente en su líquido fluir de lo que son las duras piedras de las ruinas.

Como ejemplo de la recombinación posible de tópicos pertenecientes a tradiciones diferentes, con un radical cambio de enfoque enunciativo, veamos un soneto de Bartolomé Leonardo de Argensola en el cual se integran muy hábilmente la tradición española del soldado que lamenta su amor entre las ruinas cartaginesas y la frágil hermosura femenina de la tradición del "carpe diem":

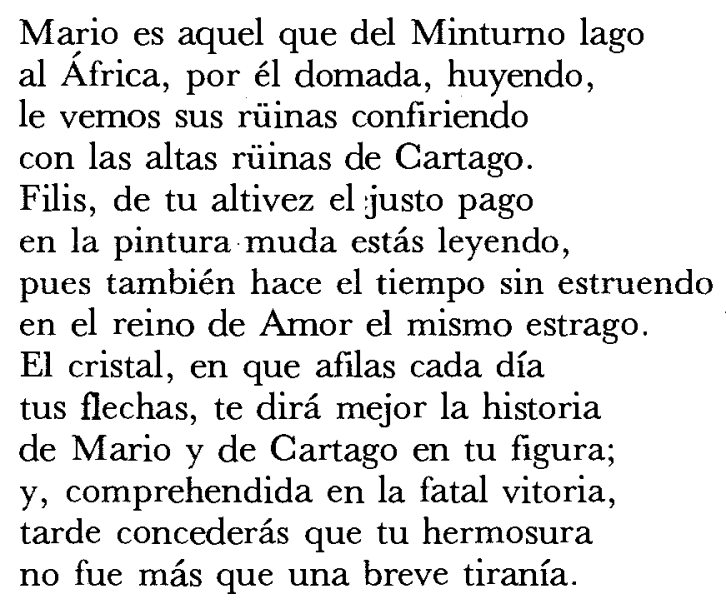

La voz del poeta en el primer cuarteto, según se ve luego en el segundo, se refiere a un cuadro de ruinas en el cual hay una figura humana (Mario) en la bien conocida postura del amante ausente que se consuela entre las ruinas de Cartago. Esto es lo que en Italia explica el poeta a la dama (Filis), quien ha de en- 
tender el cuadro como una alegoría de los estragos que hará el tiempo en su propia cara, estragos que ella verá en su espejo: "de te fabula narratur", porque el mismo tiempo que destruye con escándalo público las ciudades imperiales acabará silenciosamente con la altiva tiranía de la hermosura femenina. Es el espejo, en vez de la rosa, lo que sirve de puente entre la agresividad de la hermosura, afilando sus flechas, y el reconocimiento de su derrota. Esta ingeniosa transformación y recombinación de dos temáticas diferentes depende, como hemos visto, de varios subtextos implícitos en la tradición poética española.

Cada soneto del Siglo de Oro, aunque a menudo genéricamente clasificable ya desde su primer verso, es un núcleo autónomo que combina, con toda la coherencia y unicidad posible, fragmentos recogidos de un vasto y bien articulado texto plurilingüe que empezó a tejerse en latín durante la Antigüedad clásica y que se bordaba y se extendía durante el Renacimiento en latín, en italiano y en español. Se suponía que cada miembro de la clase letrada española era capaz de escribir por lo menos un soneto ocasional para felicitar al amigo que publicaba su libro. La brevedad del soneto y su carácter de camaleón facilitaban esta función socialmente pragmática; los subgéneros del soneto se definían según su empleo de los tópicos consagrados.

Muy diferente es el modo de definirse la epístola en verso ${ }^{10}$. Antes que la inventara Horacio, existía el género literario de la carta personal en prosa, basado en la imitación escrita de una voz conversacional dirigida apostróficamente a un amigo distante que había de leer más tarde la carta: ésta era la mitad de una conversación escindida por el espacio y el tiempo. En el mundo romano fue Cicerón quien cultivó un estilo intencionadamente coloquial, muy distinto del de sus obras oratorias y filosóficas, y luego pidió a sus amigos que hicieran circular y eventualmente publicar su

10 Véanse cuatro artículos publicados sobre la epístola en verso: ELIAS L. RIVERs, "The Horatian Epistle and its Introduction into Spanish Literature", $H R, 22$ (1954), 175-194; Claudio GullléN, "Sátira y poética en Garcilaso", $H J C, 209-233$, y Entre lo uno y lo diverso: introducción a la literatura comparada, Crítica, Barcelona, 1985, pp. 167-172; y Gonzalo Sobejano, "Confianza y literatura: las epístolas poéticas de Lope de Vega", Íns, 1990, núm. 520, 17-20. También debo mencionar aquí dos excelentes tesis inéditas: The Verse Epistle in Spanish Poetry of the Golden Age (The Johns Hopkins University, 1974) de CAROL Kayn LE VINE, y The Generic Repertoire of the Horatian Epistle and the Spanish Renaissance Verse Epistle: Assembly and Transformation (University of California, Santa Barbara, 1990) de Andrea Jean Lower. A estas dos autoras les agradezco sendas copias de sus tesis, que me han sido utilísimas. 
correspondencia; de estilo más elevado eran las cartas en prosa posteriormente publicadas por Séneca y Plinio. Partiendo de esta base, Horacio inventó un género de epístola familiar escrita en hexámetros dactílicos y en un estilo mediano o bajo que se parecía al de sus sátiras.

Después de la codificación retórica de la carta medieval en el ars dictaminis (con salutación, captatio, narración, petición y conclusión), Petrarca inició el regreso renacentista a los modelos antiguos, escribiendo muchas epístolas tanto en prosa como en verso. El Opus de conscribendis epistulis de Erasmo, elaborado a partir de 1490 y publicado en 1522, llegó a ser más tarde el tratado humanístico normativo; sin distinguir sistemáticamente entre el uso de prosa y de verso, Erasmo subrayaba la importancia del estilo familiar. Cartas vernáculas en prosa fueron publicadas primero en italiano por Pietro Aretino (1537) y, casi simultáneamente, en español por Antonio de Guevara, cuyas originalísimas Epístolas familiares en dos libros (1539 y 1541) se divulgaron por Europa. $Y$ sólo unos pocos años antes, en 1534, Ariosto había publicado en tercetos lo que él llamaba sátiras, pero que, como las epístolas de Horacio, se dirigían a amigos y parientes. Tal era la situación histórica cuando se publicaron en el famoso tomo de 1543 las primeras epístolas clásicas en versos españoles, escritas por Garcilaso, por don Diego Hurtado de Mendoza y por Juan Boscán.

Lo que en este tomo llama la atención es la notable diferencia que hay entre la breve epístola familiar horaciana dirigida en versos sueltos por Garcilaso a Boscán, y las dos epístolas más largas y elaboradamente filosóficas que se dirigían mutuamente Mendoza y Boscán; éstas se basan explícitamente en el "nil admirari", de Horacio (Epistulae, I.6) y están escritas, como las sátiras de Ariosto, en tercetos encadenados, la forma métrica bien establecida en italiano, desde la Divina comedia de Dante y los Triunfos de Petrarca, para cierto tipo de narración discursiva. Los versos sueltos, en cambio, eran una invención reciente (1515) de Trissino. Garcilaso conocía perfectamente las convenciones italianas y sabía que se desviaba de ellas al escribir una epístola en versos sueltos: a esto se refiere en los versos 5-7, cuando se niega a ser tan formal con su amigo como para "buscar estilo... tal cual a culta epístola conviene", y en los versos 8-11, cuando celebra " aqueste descuido suelto y puro, / lejos de la curiosa pesadumbre". Su estilo familiar alcanza un nivel bastante bajo al describir las posadas francesas (vv. 73-76): 
... donde no hallaréis sino mentiras, vinos acedos, camareras feas, varletes codiciosos, malas postas, gran paga, poco argén, largo camino...

Unos seis años más tarde don Diego Hurtado de Mendoza, quien probablemente conocía la epístola inédita de Garcilaso, escogió otro estilo en tercetos para su epístola dirigida a Boscán; su discurso clásicamente amistoso es torpemente interrumpido por una apóstrofe dirigida a la cruel dama "Marfira". El detalle horaciano más significativo es la evocación del retiro rústico al cual Mendoza invita nominalmente a un grupo de amigos. La contestación de Boscán es una epístola muy superior; en ella, según Reichenberger, el poeta "tries to create something new out of the classic heritage, contemporary Italian Neo-Platonic ideology, and his own experiences and observations [ . . . and] fuses Horatian, Cortesano, and Christian ideology',11.

Como ha demostrado Claudio Guillén, en los dos estudios ya citados, a principios del siglo XVI la identidad de la epístola en verso se afirmaba no aisladamente sino en contraste y en coincidencia parciales con otros dos géneros: la sátira en verso ${ }^{12}$ y la elegía. Las correlaciones entre estos tres géneros habían de seguir vacilando durante todo el Siglo de Oro; quizá habrían vacilado menos si los versos sueltos se hubieran impuesto como la métrica normal de la epístola. En las epístolas de Francisco de Aldana, que son las más importantes de la segunda mitad del siglo XVI, compiten todavía los versos sueltos con los tercetos, pero esta última es la métrica que había de dominar en el siglo xvII. En las epístolas de este siglo podemos distinguir claramente entre el tratado casi impersonal de tema moralista y la correspondencia entre amigos históricamente concretos.

Típicas de la tendencia impersonal son las epístolas muy didácticas del cura Bartolomé Leonardo de Argensola; éste en 1604 dirigió a su amigo Francisco de Eraso una larga epístola sobre su decisión de abandonar sus pretensiones cortesanas, la cual empieza con este terceto:

11 Arnold G. Reichenberger, “Boscán's Epistola a Mendoza”, HR, 17 (1949), 1-17.

12 Sobre la sátira en verso véase el estudio de Lía Schwartz Lerner, "Formas de la poesía sátirica en el siglo XVII: sobre las convenciones del género", Edad de Oro, 6 (1987), 215-234. 
Hoy, Fabio, de la Corte me retiro

a dilatar, si puedo, en una aldea

algunos años mi postrer suspiro...

Notemos cómo el nombre particular del amigo Eraso es sustituido aquí por lo que podemos llamar el nombre génerico de "Fabio", mero apoyo retórico para una serie de tópicos relacionados con el retiro al campo. Sería sólo un paso más el que diera Góngora en su "Epístola moral sin Fabio" (la etiqueta es de Gerardo Diego) de 1609, en la que se dirige en su salutación, no a un amigo, sino a los arroyos de su huerta cordobesa:

Mal haya el que en señores idolatra y en Madrid desperdicia sus dineros, si ha de hacer al salir una mohatra.

Arroyos de mi huerta lisonjeros

(¿lisonjeros?: mal dije, que sois claros):

Dios me saque de aquí y me deje veros...

Ya no es realmente epístola este poema, porque el poeta no se dirige a ninguna figura humana sino, apostrófica y burlescamente, a los arroyos, a la soledad, y finalmente a la mula en la que se monta.

El ejemplo ahora mejor conocido de la epístola impersonal, aunque escrito en 1613, no se publicó hasta 1768; hecha famosa por Menéndez Pelayo, la "Epístola moral a Fabio", del poco conocido poeta andaluz Andrés Fernández de Andrada, fue definitivamente canonizada en 1977 por la edición crítica y comentada de Dámaso Alonso ${ }^{13}$. Es en efecto un brillante resumen de la más castiza tradición horaciana: el cortesano, huyendo de la corte real de Madrid, invita a su amigo a acompañarle filosóficamente en terrenos andaluces.

Totalmente diferente por su activismo político es la muy conocida "Epístola satírica y censoria contra las costumbres presentes de los castellanos, escrita a don Gaspar de Guzmán, conde de Olivares, en su valimiento' (1621) de Quevedo; es formalmente innovadora porque empieza no con la salutación epistolar escrita al conde sino con una protesta en forma oral contra una persona anónima que intenta callarle:

${ }^{13}$ La "Epístola moral a Fabio", de Andrés Fernández de Andrada: edición y estudio, Gredos, Madrid, 1978. 
No he de callar, por más que con el dedo, ya tocando la boca, o ya la frente, silencio avises, o amenaces miedo.

La salutación ("Señor excelentísimo..."), o sea el principio de la carta misma, se aplaza hasta el verso 25 . Pero, en términos horacianos, es más bien sátira que epístola; véase el ya citado estudio de Lía Schwartz Lerner.

El otro subgénero más familiar y personal de la epístola horaciana encuentra en Lope de Vega a su maestro; las epístolas de este poeta, tan hábil en la poetización de su propia vida, fueron estudiadas por Carol Kayn Le Vine en su tesis de 1974 y han sido caracterizadas en 1990 por Gonzalo Sobejano en un breve ensayo sustancioso. Según explica éste, en las catorce epístolas que Lope mismo publicó entre 1621 y 1624 , cuando tenía casi 60 años, el poeta y sacerdote maduro discurre graciosamente sobre temas variadísimos, relacionados todos con su propia persona y con la de su amigo, quien es en cada caso individualmente identificable y no se convierte en un "Fabio" genérico: las murmuraciones cortesanas se mezclan con íntimos detalles autobiográficos tales como la desordenada vida familiar que llevaba Lope con Marta de Nevares y sus hijos, su preocupación por el reconocimiento literario y por sus necesidades económicas, su envidiosa admiración a Góngora. Es muy original, por ejemplo, su epístola titulada " Belardo a Amarilis", la cual se dirige no a un amigo masculino sino a una lejana dama peruana, quien en una epístola en estancias ${ }^{14}$ se había preocupado por la salvación espiritual de Lope; éste le explica su decisión religiosa:

Dejé las galas que seglar vestía; ordenéme, Amarilis, que importaba el ordenarme a la desorden mía.

Esta epístola es en efecto toda una apologia pro vita sua. Y el género epistolar, como han sugerido tanto Bajtín como Guillén, de alguna manera anticipaba el discurso dialogado y cotidiano de la novela moderna.

14 Véanse los estudios de Georgina Sabat-Rivers, "Amarilis' Verse Epistle and her Love for Lope: Seeing and Hearing", en Studies in Honor of Elias Rivers, Scripta Humanistica, Potomac, MD, 1989, pp. 152-168, y "Amarilis: innovadora peruana de la epístola horaciana", $H R, 58$ (1990), 455-467. 
Si el soneto se define claramente por la forma métrica de su significante, y si la epístola se define más complejamente por su forma enunciativa y temática, la silva es un género todavía más escurridizo ${ }^{15}$. En España la palabra latina "silva" se aplicaba desde principios del siglo XVII tanto a una forma métrica como a un género más o menos clásico asociado con las Silvae de Estacio. Pero son heterogéneos los 32 poemas de este autor romano; quizá lo más típico sea la écfrasis, la artificiosa descripción, por ejemplo, de una casa de campo también muy artificiosa ${ }^{16}$. Pero el único contacto directo entre la silva española y las de Estacio parece ser la libre traducción imitativa que hizo Quevedo entre 1605 y 1611 del breve poema (Silvae, V.4) del poeta latino ${ }^{17}$. La apóstrofe dirigida por el poeta al dios del sueño es lo que da estructura retórica a ambos poemas.

Fue Eugenio Asensio quien primero llamó la atención sobre la importancia de la silva genérica en Quevedo; pero de los 36 poemas clasificados como silvas en las ediciones primitivas, sólo 22 son silvas métricas. Tomando como representativos de sus silvas los poemas posteriormente titulados "A una fuente" (que empieza "QQué alegre que recibes") y "Al pincel" ("Tú, si en cuerpo pequeño"), podemos señalar otra vez la apóstrofe como la estructura enunciativa que define al género. Y lo mismo podemos observar en las silvas contemporáneas de Francisco de Rioja, las cuales se dirigen apostróficamente a Apolo, a abstracciones personificadas y a varias especies de flor. A base de estos pocos ejemplos, podemos sacar la conclusión provisional de que hacia el año 1612 se fraguaba con claridad clásica un género estaciano español.

Pero precisamente al año siguiente, en 1613, empezó a circularse en Madrid la Primera soledad de Góngora. No hay duda de que este poeta ya maduro, que tenía casi 20 años más que Quevedo y Rioja, respondía en su magno poema al desafío de la nue-

${ }^{15}$ Además del ya citado estudio de A. Alatorre, véanse los de Eugenio Asensio, "Un Quevedo incógnito: las silvas", Edad de Oro, 2 (1983), 9-48; de E. L. Rivers, "La problemática silva española", $N R F H$, 36 (1988), 249-260; y de A. EGIDO, "La silva en la poesía andaluza del Barroco (con un excurso sobre Estacio y las obrecillas de Fray Luis)", Criticón, 1989, núm. 46, 5-39.

16 Véanse las páginas de Z. Pavlovskis dedicadas a las Silvae en su monografía titulada Man in an Artificial Landscape: The Marvels of Civilization in Imperial Roma Literature, Brill, Amsterdam, 1973.

17 Véase el estudio exhaustivo de J. O. Crosby y L. Schwartz Lerner, "La silva "El sueño" de Quevedo: génesis y revisiones", $B H S, 63$ (1986), 111-126. 
va moda de la silva poética. Utilizando la silva métrica en su poema mucho más largo y muy diferente, se proponía superar los estrechos límites estacianos aceptados e impuestos por Quevedo y Rioja; en su poema de más de mil versos Góngora reprimía rigurosamente la tradicional retórica de la presencia personal del poeta, representada por la apóstrofe persistente, y, como ha demostrado Nadine $\mathrm{Ly}^{18}$, evitó cuidadosamente los deícticos del yo poético, cultivando una nueva retórica de la ausencia. En su conclusión, la erudita francesa afirma que Góngora en efecto abandonaba con sus Soledades el mundo cerrado de los géneros clásicos:

Este poema, que no encaja en ningún molde preexistente, es, a mi parecer, el primer poema "moderno" o sea el primero que no se pueda definir sino como poema. Sólo habrá que dar un paso más hacia la destrucción de la red asociativa o metafórica, para que a la desaparición de los límites genéricos, correspondan un lenguaje o una escritura fundados en analogías nuevas, desligadas a su vez de un ritual discursivo llevado por las Soledades gongorinas a los extremos de la belleza y de la sofisticación ${ }^{19}$.

Pocos poetas después de Góngora fueron capaces de seguir su ejemplo revolucionario; quizá el único caso notable fue el de Sor Juana Inés de la Cruz en su Sueño, poema también único en toda la poesía del Siglo de Oro, titulado en su primera edición (1692): "Primero sueño, que así intituló y compuso la madre Juana Inés de la Cruz, imitando a Góngora".

Al principio del cuento "Las babas del diablo", hecho famoso por la versión cinematográfica de Antonioni titulada Blow Up, el narrador de Cortázar se imagina la posibilidad de acoplar una cámara fotográfica directamente con una máquina de escribir para poder, sin intervención subjetiva humana, convertir en texto escrito una escena visual. Metafóricamente, podemos imaginarnos nosotros que el poeta renacentista producía sus textos acoplando un género clásico a una enciclopedia de citas, tal como la Officina de Ravisius Textor, por ejemplo, que era una bien organizada colección de fragmentos poéticos que encarnaban en versos los tópicos y los doxa, o sea las opiniones tradicionales, a los cuales se suponía que regresarían siempre los verdaderos poetas. Estas opi-

18 "Las Soledades: «...Esta poesía inútil..."”, Criticón, 1985, núm. 30, 7-42. Véase también el ensayo de JoHn Beverley, "Confusion and Construction in the Soledades", Dispositio, 3 (1978), 295-313.

${ }^{19}$ Art. cit., pp. 41-42. 
niones no se consideraban de ninguna manera discutibles; constituían simplemente la ideología implícita del humanismo, la creencia en una esencial naturaleza humana que no cambiaba nunca.

Los poemas que hemos mirado someramente no eran de ninguna manera los productos individualistas de "sujetos libres" $2 C$ que funcionaran independientemente de cualquier sistema cultural: cada poema se asociaba con un género, que definía un tipo de situación social según ciertos conjuntos de ideas, de relaciones y de artificios retóricos apropiados. La educación clásica, o formación ideológica, de los poetas que habían estudiado en Alcalá o en Salamanca les proveía de una codificación de las frases apropiadas para cualquier situación literaria. "La habilidad discursiva es un capital simbólico que se adquiere en el proceso de la socialización", según dice John Frow ${ }^{21}$, un proceso que dependía de la estructura clasista de la sociedad española, la cual privilegiaba a los jóvenes nobles o ricos o clericales que tenían acceso a maestros de latín para poder asistir luego a la universidad, donde seguirían aprendiendo a pensar y escribir según ciertos géneros de discurso establecidos:

By establishing the limits of the sayable, genre allows the unsaid to be said without being said, i.e., without the speaker taking responsibility for the enunciation of the message. And by defining that which can be taken for granted it establishes the stable field of meanings, the ideological second nature, which constitutes the real ${ }^{22}$.

Lo real de la España del Siglo de Oro era lo que discursivamente afirmaban (y punitivamente imponían) la Iglesia y la Monarquía, la Inquisición y el código de honor, la tradición humanista europea y las complejas conversaciones y praxis cotidianas de las calles y los campos castellanos. Basados implícitamente en todo esto, los sonetos y las epístolas y las silvas eran otros tantos juegos discursivos con sus propias reglas constitutivas; los poetas y sus lectores, haciendo sus jugadas convencionales, que eran a veces brillantes, participaban en la producción, la perpetuación e incluso la crítica de la estancada realidad española.

Elias L. Rivers State University of New York at Stony Brook

20 "Free subjects" son las palabras de JoHn Frow en su ensayo "Discourse Genres", Journal of Literary Semantics, 9 (1980), 72-81.

21 Ibid., p. 78.

${ }^{22}$ Ibid., p. 79. 